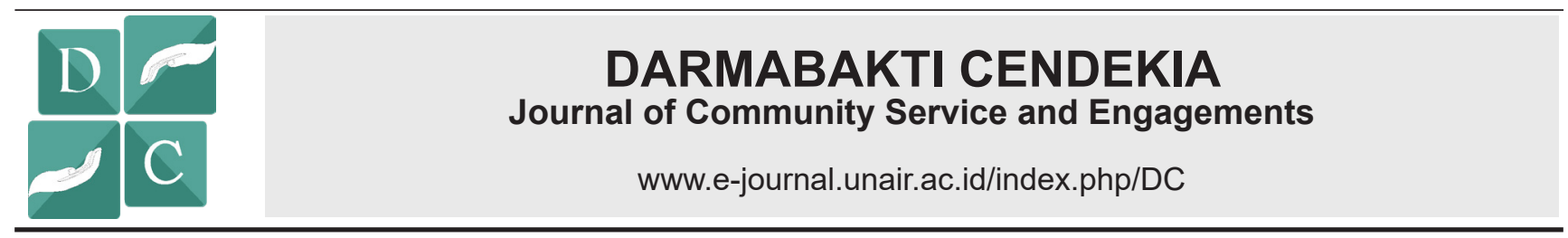

\title{
COMMUNITY EMPOWERMENT THROUGH SULFUR SOAP PREPARATION FOR DERMATITIS PREVENTION
}

\author{
PEMBERDAYAAN MASYARAKAT MELALUI PELATIHAN \\ PEMBUATAN SABUN SULFUR UNTUK PENCEGAHAN \\ DERMATITIS
}

Scope:

Health

Amirah Adlia ${ }^{*}$, Sakinah Aljuffrie ${ }^{2}$, Annis Catur Adi $^{2}$, Deandra Ardya Regitasari ${ }^{2}$, Vidya Anggarini Rahmasari $^{2}$, Heni Rachmawati ${ }^{1}$

${ }^{1}$ School of Pharmacy, Institut Teknologi Bandung, Bandung-Indonesia

${ }^{2}$ Faculty of Public Health, Universitas Airlangga, Surabaya-Indonesia

\begin{abstract}
A B S T R A C T
Background: As a country with a tropical climate, Indonesia has the risk to have many disease problems, such as skin disorder or dermatitis. Dermatitis is an either acute, sub-acute, or chronic inflammatory skin disease. One of therapies is using sulfur compound. Purpose: The objective of this program was to improve public awareness of Tulung Agung Regency on the importance of health care, to train people preparing soap containing sulfur, and to help the people to empower the economic community through home industry initiation. Methods: This program was done by motivation generating, counseling, advocacy, and education. The activities were performed through counseling about skin diseases, causes, the prevention and treatment of the disease with sulfur soap, demonstration and providing training to the community about sulfur soap. Results: The training on handmade soap preparation was conducted at the Village Hall of Mojosari, Kauman, Tulungagung, on July 28-29th 2019, and was attended by 20 female participants. The socialization program was carried out by providing technical guidance, visual exposure of materials, packaging training through small groups. Conclusion: This training program of soap containing sulfur preparation attracted public attention to gain the science, knowledge, and skill increase business motivation, knowledge, and community skills as well as motivation generation to apply a simple technology of soap containing sulfur manufacturing.
\end{abstract}

\section{A B S T R A K}

Latar belakang: Sebagai negara dengan iklim tropis, Indonesia beresiko memiliki banyak permasalahan penyakit, di antaranya penyakit kulit atau dermatitis. Dermatitis adalah penyakit inflamasi pada kulit yang bersifat akut, sub-akut, atau kronis, disebabkan oleh berbagai faktor. Salah satu pengobatan yang dilakukan adalah menggunakan senyawa sulfur. Tujuan: Kegiatan ini bertujuan untuk meningkatkan kesadaran masyarakat Kabupaten Tulung Agung akan pentingnya pemahaman pemeliharaan kesehatan kulit, memberikan pelatihan pembuatan sabun sulfur, serta membantu memberdayakan potensi ekonomi masyarakat melalui inisiasi industri rumah tangga sabun sulfur. Metode: Program pengabdian masyarakat dilakukan dengan metode pembangkitan motivasi, penyuluhan, advokasi dan edukasi. Bentuk kegiatan melalui penyuluhan tentang penyakit kulit, sumber pencetus, serta cara mencegah dan mengobati salah satunya dengan sabun sulfur, demo pembuatan sabun mengandung sulfur serta pelatihan masyarakat untuk memproduksi sabun sulfur. Hasil: Pelatihan pembuatan sabun handmade dilaksanakan di Balai Desa Mojosari, Kauman, Tulungagung, pada tanggal 28 - 29 Juli 2019, dan dihadiri oleh 20 warga desa. Sosialisasi dilakukan dengan memberikan petunjuk teknis, pemaparan materi secara visual, pelatihan pengemasan, serta pembentukan kelompok-kelompok masyarakat untuk kegiatan pelatihan pembuatan sabun. Kesimpulan: Kegiatan pelatihan pembuatan sabun menarik banyak minat warga desa untuk menimba ilmu, pengetahuan, dan ketrampilan, serta meningkatkan motivasi usaha melalui penerapan teknologi sederhana untuk pembuatan sabun sulfur.

\section{ART ICLE INFO}

Recieved 24 September 2019

Accepted 4 November 2019

Online 20 December 2019

*Correspondence (Korespondensi): Amirah Adlia

E-mail:

amirah711@gmail.com

Keywords:

Sulfur soap; Dermatitis; Skin desease

Kata kunci:

Sabun sulfur; Dermatitis; Penyakit kulit 


\section{PENDAHULUAN}

Data dari Dinas Kesehatan Provinsi Jawa Timur, penderita dermatitis kontak alergi pada tahun 2013 sampai triwulan III sebanyak 18.702 penderita, dan selalu menduduki peringkat 6 besar dari 10 penyakit lainnya. Dermatitis adalah penyakit peradangan pada kulit yang menginfeksi sekitar 20\% dari seluruh populasi dunia secara umum yang bersifat akut, subakut, atau kronis. Peradangan kulit (epidermis dan dermis) sebagai respon terhadap pengaruh faktor eksogen dan endogen, menimbulkan kelainan klinis berupa efloresensi polimorfik dan keluhan gatal (Djuanda, 2010). Terdapat berbagai macam dermatitis, dua di antaranya adalah dermatitis kontak dan dermatitis okupasi. Dermatitis kontak adalah kelainan kulit yang bersifat polimorf sebagai akibat terjadinya kontak dengan bahan eksogen (Dinas Kesehatan Jawa Timur, 2014).

Dermatitis dapat disebabkan oleh berbagai faktor. Faktor langsung (direct causes) meliputi paparan dengan agen seperti bahan kimia atau pupuk urea, serta faktor tidak langsung (indirect causes) meliputi penyakit yang telah diderita sebelumnya, usia, lingkungan, dan kebersihan perorangan (personal hygiene). Menurut Danisa Diandra Safarina (2014), faktor lingkungan yang dapat memicu terjadinya dermatitis adalah polutan, alergen, makanan, dan mikro organisme (Djuanda, 2010).

Paparan dengan suatu agen kimia, seperti pupuk urea, dapat menyebabkan kerusakan sel kulit bagian luar. Semakin lama waktu dan semakin banyak jumlah bahan yang digunakan untuk melakukan kontak, maka semakin buruk kerusakan sel kulit yang terjadi. Kerusakan yang terjadi pada sel kulit dapat mengakibatkan kemungkinan besar kerusakan sel bagian dalam dan memperburuk kondisi dermatitis (Safarina, 2014). Selain dari bahan kimia, dermatitis juga dapat disebabkan oleh pola kebersihan diri. Banyak gangguan kesehatan yang diderita seseorang karena tidak terpeliharanya kebersihan perorangan dengan baik. Gangguan fisik yang sering terjadi adalah gangguan integritas kulit, gangguan membran mukosa mulut, infeksi pada mata dan telinga, dan gangguan fisik pada kuku (Handoko, 2008).

Pola kebersihan diri juga berperan penting dalam memicu terjadinya kondisi dermatitis. Petani cenderung menggunakan air sungai atau air yang tidak bersih untuk membersihkan diri selama di sawah karena tidak adanya sumur atau sumber air bersih di setiap lahan sawah. Pilihan personal terkait pilihan dalam membersihkan diri juga mempengaruhi kebersihan perorangan. Oleh karena itu, usia, hidrasi, iklim, dan lingkungan kerja menjadi faktor dalam kebiasaan dan pola kebersihan diri (Harrianto, 2012).

Masyarakat memiliki berbagai cara dalam pengobatan dermatitis, antara lain penggunaan kortikosteroid secara topikal yang efektif pada kondisi fase akut (Riyadi and Harmoko, 2012). Salep kortikosteroid memiliki konsentrasi yang sedang yang harus dioleskan sebanyak tiga kali sehari pada bagian-bagian kulit yang sakit. Pemberian salep ini dapat membantu meredakan gejala-gejala pruitus dan mengendalikan inflamasi (Riyansari, 2015). Pola perilaku pengobatan dermatitis mandiri seperti ini dilakukan oleh separuh responden (Riyadi and Harmoko, 2012). Berdasarkan hasil penelitian sebelumnya, responden yang melakukan pemeriksaan ke tenaga kesehatan memiliki dukungan yang baik. Keluarga memperhatikan kondisi gatal pada kulit, memberikan saran, serta mengusahakan dana untuk pengobatan. Sedangkan responden yang melakukan pengobatan sendiri dan tidak melakukan pengobatan cenderung memiliki dukungan yang kurang. Beberapa faktor yang menjadi alasan dalam pengobatan ke pelayanan kesehatan adalah kedekatan jarak dan kemudahan dalam menjangkau pelayanan kesehatan.

Cara pengobatan dengan pemberian salep tersebut dapat membantu meredakan gejala-gejala dan mengendalikan inflamasi (Riyansari, 2015). Akan tetapi, pengobatan seperti ini dapat memicu efek samping seperti hilangnya jaringan kolagen kulit, gatal, folikulitis, dan dermatitis kontak alergi. Oleh karena itu, pembuatan sabun mengandung sulfur memiliki keunggulan dan manfaat dari segi kesehatan dan ekonomi.

Sulfur atau belerang merupakan unsur kimia murni non-logam yang tersedia di alam. Sulfur telah lama digunakan sebagai sediaan topikal atau sediaan yang digunakan di kulit. Ada dua bentuk sulfur yang tercantum sebagai monografi di United States Pharmacopoeia (USP), yaitu sublimed sulfur dan precipitated sulfur. Precipitated sulfur diperoleh dari hasil reaksi sublimasi sulfur yang dididihkan dengan air dan kapur, dan ditambahkan asam klorida (Hutagaol, 2018). Sublimed sulfur dan precipitated sulfur memiliki perbedaan warna dan kelarutan. Precipitated sulfur memiliki ukuran partikel yang lebih kecil, sehingga memiliki efek terapeutik yang lebih baik dibandingkan sublimed sulfur (Hutagaol, 2018).

Sulfur banyak digunakan pada terapi penyakit kulit, seperti jerawat, seborrheik dermatitis, skabies, dan rosasea. Mekanisme kerja sulfur pada terapi jerawat dan sebarrhoik dermatitis adalah keratolitik (Hutagaol, 2018). Sulfur diduga berinteraksi dengan sistein pada keratinosit. Sistein merupakan salah satu asam amino yang terkandung dalam stratum korneum yang memiliki peran penting pada proses keratinisasi normal. Sulfur juga memiliki aktivitas sebagai antifungi. Ketika diaplikasikan di kulit, sulfur akan dikonversikan menjadi asam pentathionat oleh bakteri yang ada di kulit dan keratinosit. Selain itu, aktivitas keratolitik dari sulfur juga dapat 
membantu menghilangkan jamur dari stratum korneum.

Kegiatan pengabdian masyarakat ini bertujuan untuk meningkatkan kesadaran masyarakat Kabupaten Tulungagung terkait pentingnya pemahaman pemeliharaan kesehatan, memberdayakan masyarakat Tulungagung untuk memulai usaha industri rumah tangga yang menghasilkan produk yang dapat digunakan untuk membantu mengatasi masalah kesehatan kulit. Bentuk kegiatan melalui penyuluhan tentang penyakit kulit, sumber pencetus, serta cara mencegah dan mengobati salah satunya dengan sabun sulfur, demo pembuatan sabun mengandung sulfur serta memberikan pelatihan kepada masyarakat untuk memproduksi sabun tersebut, baik untuk konsumsi sendiri maupun untuk komersial.

\section{METODE}

Program pengabdian masyarakat dilakukan dengan menggunakan metode pembangkitan motivasi, penyuluhan, advokasi, dan edukasi. Motivasi dan penyuluhan merupakan upaya untuk mengawali proses pemberdayaan yang bertujuan untuk menghasilkan perubahan positif masyarakat terhadap manfaat sabun sulfur, peningkatan pemahaman, dan kesanggupan dalam membuat sabun sulfur secara mandiri. Selain itu, kegiatan pengabdian masyarakat merupakan sarana untuk mentransfer pengetahuan terkait penggunaan sabun sulfur sehingga dapat digunakan masyarakat dengan baik. Penyuluhan ini diharapkan dapat menambah pengetahuan tentang cara pembuatan sabun sulfur kepada masyarakat Tulungagung. Edukasi masyarakat bertujuan untuk melakukan transformasi pengetahuan dan kecakapan dalam membuat sabun sulfur. Dengan kegiatan ini, kelompok sasaran diharapkan memiliki wawasan pengetahuan dan ketrampilan. Kegiatan edukasi meliputi sosialisasi dan demo pembuatan sabun sulfur. Advokasi merupakan pendampingan pada kelompok yang bertujuan untuk menjaga konsistensi kegiatan pemberdayaan pada kelompok sasaran, sehingga sanggup dan mampu melakukan kegiatan pembuatan sabun sulfur secara mandiri. Program pengabdian masyarakat tentang penbuatan sabun sulfur dilakukan pada program Kemitraan Masyarakat di Kabupaten Tulungagung, Jawa Timur, pada tanggal 20 - 21 Juli 2019.

\section{HASIL DAN PEMBAHASAN}

Sulfur merupakan unsur yang telah digunakan selama berabad - abad untuk dermatologi. Sulfur dapat bersifat anti seboroik, anti-acne, anti-scabies, anti bakteri dan anti jamur. Sabun sulfur berguna untuk mengatasi infeksi pada kulit (Handoko, 2008). Kandungan sulfur yang terdapat pada sabun relatif rendah sehingga membuatnya tidak perlu dilakukan pengurangan konsentrasi untuk penggunaan anak - anak dan bayi. Keuntungan penggunaan sulfur pada sabun adalah sumbernya yang berlimpah di alam dan mudah diperoleh, murah dan aman. Efek samping yang dapat ditimbulkan pada penggunaan sabun sulfur adalah iritasi pada kulit jika penggunaannya sangat berlebihan dan pada orang hipersensitivitas, serta kekeringan pada kulit yang berlebihan (Tompkins, 2000).

Pelatihan pembuatan sabun handmade dilaksanakan di Balai Desa Mojosari, Kauman Tulung Agung pada tanggal 28 - 29 Juli 2019 (Gambar 1). Program sosialisasi pengabdian masyarakat dilakukan di Balai desa Mojosari yang dihadiri oleh masyarakat daerah setempat, umumnya kaum wanita. Peserta yang hadir berjumlah 20 orang dan umumnya ibu rumah tangga tidak bermata pencaharian (pengangguran). Kegiatan sosialisasi dilakukan dengan memberikan petunjuk teknis terkait dengan pembuatan sabun. Petunjuk teknis dibuat dengan cara sesederhana mungkin agar mudah dipahami dan dapat diimplementasikan oleh masyarakat dengan tepat (Gambar 2). Kegiatan sosialisasi dilakukan dengan pemaparan materi secara visual menggunakan power point/ slide supaya masyarakat tertarik dan memperoleh gambaran secara jelas tentang proses pembuatan sabun sulfur.

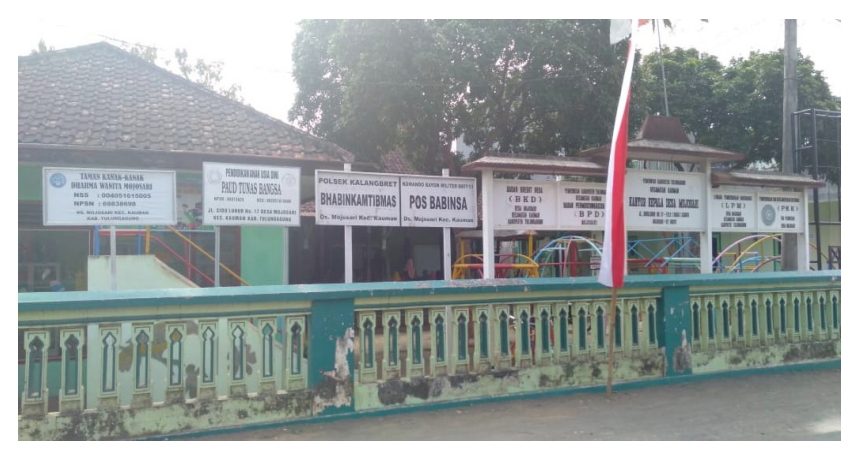

Gambar 1. Tempat pelaksanaan pembuatan sabun.

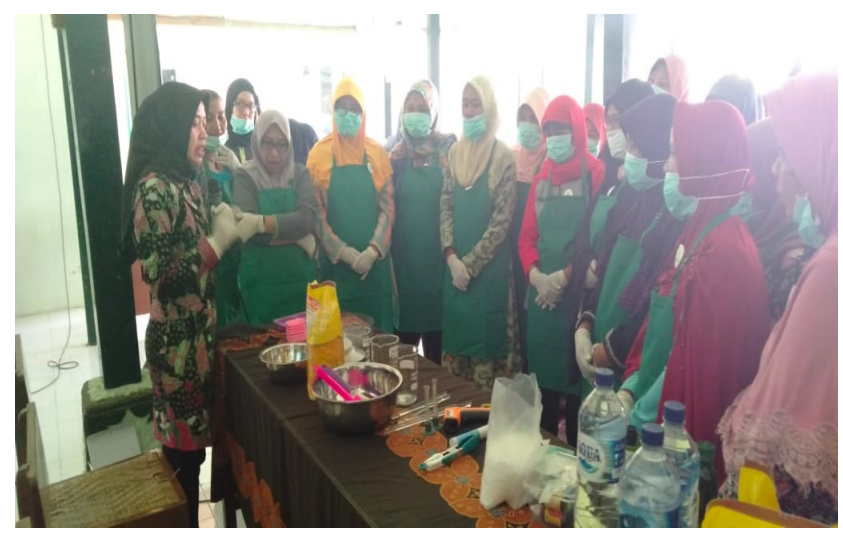

Gambar 2. Pemberian petunjuk teknis tentang pembuatan sabun sulfur ke peserta. 
Langkah-langkah pembuatan sabun ditunjukkan dalam bagan Gambar 3. Langkah pertama menyiapkan cetakan, dilanjutkan dengan menimbang air dan $\mathrm{NaOH}$. Kemudian dilakukan penimbangan minyak kelapa sesuai dengan formula, selanjutnya minyak dituang dengan larutan $\mathrm{NaOH}$ dengan hati-hati. Langkah selanjutnya adalah memasang penutup blender, dan meletakkan kain di atas penutup tersebut untuk menghindari cipratan. Bagian akhir proses adalah pewarnaan dan pemberian pengharum, selanjutnya masa sabun dicetak pada cetakan yang sudah tersedia (Gambar 4).

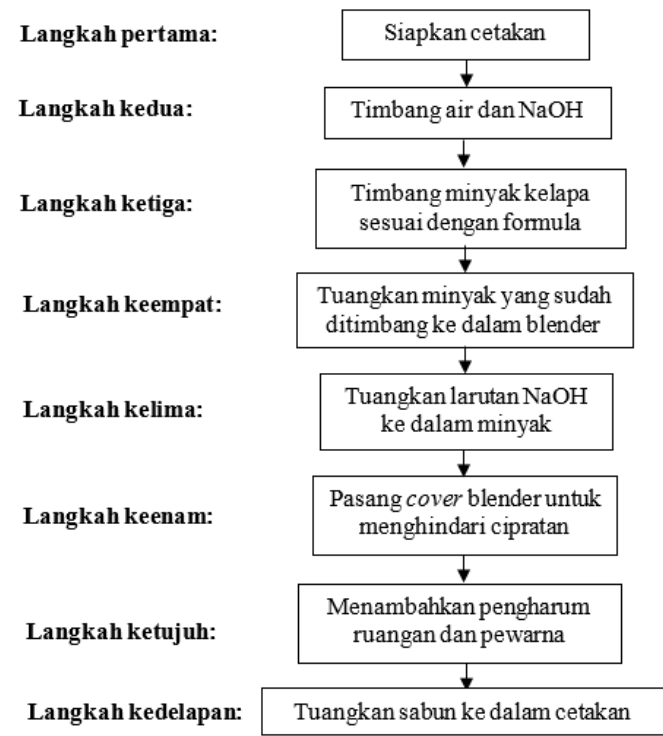

Gambar 3. Bagan cara pembuatan sabun sulfur.

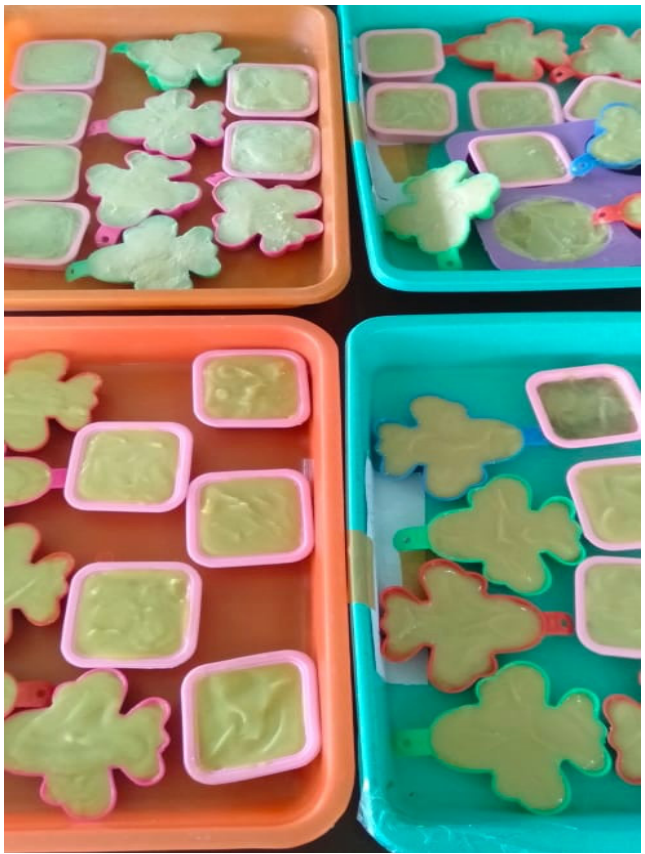

Gambar 4. Hasil pembuatan sabun sulfur.

Setelah proses pembuatan sabun sulfur selesai dilaksanakan, dilanjutkan dengan tahap pelatihan pengemasan (packaging) secara sederhana dengan menggunakan plastic wrap. Selanjutnya dibentuk kelompok kerja untuk mengefektifkan kegiatan pelatihan dan melatih kerja sama dalam kelompok. Dari kelompok-kelompok ini dibuat perlombaan ketrampilan, kekompakan, kebersihan, kerapihan dan keberhasilan produk sabun sulfur. Hasil kegiatan pengabdian masyarakat ini memberikan peluang besar pada masyarakat untuk memberdayakan sumber daya alam lokal (sulfur), mengolah dalam bentuk produk yang lebih bernilai guna, serta yang tidak kalah penting adalah menginisiasi kreativitas serta semangat usaha untuk kemandirian ekonomi keluarga. Pada saat kegiatan pengabdian masyarakat, juga hadir ketua Forum IKM Tulungagung, yang memberi harapan kepada masyarakat peserta penyuluhan untuk mulai mempraktekkan dalam usaha bisnis kecil.

\section{KESIMPULAN DAN SARAN}

Kegiatan pengabdian masyarakat berupa penyuluhan pembuatan sabun mengandung sulfur yang memberdayakan sumber daya alam lokal, mendapat sambutan yang luar biasa dari masyarakat Tulungagung, terutama kaum wanita atau ibu rumah tangga. Berdasarkan hasil kegiatan ini, pemahaman masyarakat akan kesehatan dan pemeliharaannya, upaya pengobatan mandiri melalui pembuatan sabun mengandung sulfur, serta semangat peserta untuk mulai usaha bisnis mengalami peningkatan. Masyarakat dilengkapi dengan fasilitas dan bahan untuk sabun sulfur agar kegiatan ini dapat dilanjutkan dan dirasakan manfaatnya untuk masyarakat yang lebih luas.

Pelatihan lanjutan untuk pembuatan sabun padat saja dan sabun jenis lain seperti sabun cair maupun produk yang lain masih diperlukan sehingga menambah keragaman produk yang dapat diproduksi oleh masyarakat Tulungagung terutama Desa Mojosari.

\section{UCAPAN TERIMA KASIH}

Kegiatan Pengabdian Masyarakat ini sepenuhnya didanai oleh Institut Teknologi Bandung melalui skema P3MI tahun 2019 yang diberikan kepada Kelompok Keahlian Farmasetika, Sekolah Farmasi ITB. Penulis juga mengucapkan terima kasih kepada PT. Rumah Inovasi Natura, Surabaya, yang turut berperan melancarkan kegiatan. Selain itu, ucapan terima kasih juga disampaikan kepada Ibu Miswati dan Ibu Anna Smedyah Putri yang telah membantu memberdayakan partisipasi masyarakat Desa Mojosari, beserta seluruh aparat kelurahan yang telah memfasilitasi pelaksanaan kegiatan tersebut. 


\section{DAFTAR PUSTAKA}

Dinas Kesehatan Jawa Timur. 2014. Profil Kesehatan Provinsi Jawa Timur Tahun 2013. Surabaya: Dinas Kesehatan Jawa Timur.

Djuanda, A., Hamzah, M., Aisah, S. 2010. Ilmu Penyakit Kulit dan Kelamin (Edisi Keenam). Jakarta: Fakultas Kedokteran Universitas Indonesia.

Handoko, R.P. 2008. Skabies: Ilmu Penyakit Kulit dan Kelamin (Edisi 5). Jakarta: Fakultas Kedokteran Universitas Indonesia.

Harrianto. 2012. Penyakit Akibat Kerja Karena Pajanan Zat Kimia. Jakarta: EGC.

Hutagaol, E.R. 2018. Faktor-Faktor yang Berhubungan Dengan Kejadian Dermatitis Kontak Akibat Kerja Pada Pedagang Ikan di Pasar Tradisional AL-Modern Gudang Lelang, Teluk Betung, Kota Bandar Lampung. Skripsi. Lampung: Fakultas Kedokteran Universitas Lampung.

Riyadi, S., Harmoko. 2012. Standard Operating Procedure dalam Praktek Klinik Keperawatan Dasar. Yogyakarta: Pustaka Pelajar.

Riyansari, S. 2015. Hubungan Pola Kebersihan Diri Dengan Terjadinya Gangguan Kulit Pada Petani Padi Di Kelurahan Nanggulan Wilayah Kerja Puskesmas Cawas I Kabupaten Klaten. Skripsi. Surakarta: Universitas Muhammadiyah Surakarta.

Safarina, D.D. 2014. Karakteristik Penderita Dermatitis Atopik di Poliklinik RSUP Dr. Karyadi Semarang. Skripsi. Semarang: Universitas Diponegoro.

Tompkins, H.P. 1940. Scabies: Its Treatment with a Special Sulphur Soap. Western Journal of Medicine Vol. 53(6). Pp. 271-272. 